\title{
Suspension for Injection in Pre-filled Pen
}

National Cancer Institute

\section{Source}

National Cancer Institute. Suspension for Injection in Pre-filled Pen. NCI Thesaurus. Code C149968.

Medicinal product consisting of a suspension for injection presented in a pre-filled pen. 